Article

\title{
Effect of Selective Encapsulation of Hydroxypropyl- $\beta$-cyclodextrin on Components and Antibacterial Properties of Star Anise Essential Oil
}

\author{
Guangjie Zhang ${ }^{1,2}$, Chao Yuan ${ }^{3,4, *(1)}$ and Yonghai Sun ${ }^{1, *}$ \\ 1 College of Food Science and Engineering, Jilin University, No. 5333, Xi'an Road, Changchun 130062, China; \\ zhangguangjie000@163.com \\ 2 School of Biotechnology and Food, Anyang Institute of Technology, Huanghe Road, Anyang 455000, China \\ 3 School of Food Science and Engineering, Qilu University of Technology (Shandong Academy of Sciences), \\ Jinan 250353, China \\ 4 Postdoctoral Workstation, Henan Yalinjie Biological Technology Co., LTD, Anyang 455000, China \\ * Correspondence: wheat1997@yahoo.com (C.Y.); sunyh@jlu.edu.cn (Y.S.); \\ Tel.: +86-531-89631195 (C.Y.); +86-431-5094908 (Y.S.)
}

Received: 17 March 2018; Accepted: 19 April 2018; Published: 9 May 2018

\begin{abstract}
Star anise essential oil (SAEO) is a plant essential oil with good antibacterial activity, but its applications are limited due to its high volatility, strong smell, and unstable physical and chemical properties. The effect of selective encapsulation of SAEO by hydroxypropyl- $\beta$-cyclodextrin (HPCD) on its compositions, volatility stability and antibacterial activity was investigated. The GC-MS results indicated that the compositions reduced and content of the compositions of SAEO changed after encapsulation. Most of the components in SAEO were successfully encapsulated by HPCD, which can be supported by data from FTIR and ${ }^{1} \mathrm{H}$ NMR. According to the molecular modeling results, the three guest molecules (trans-anethole, estragole and trans-foeniculin) were all docked in the cavity of HPCD on the isoallyl (or allyl) side. The volatile stability of SAEO before and after encapsulation was evaluated by electronic nose, and the results confirmed that encapsulation significantly reduced the irritating smell of SAEO and makes the clathrate have a sustained release effect. Furthermore, in the antibacterial test, the selective encapsulation of HPCD improved the inhibition effect of SAEO on Rhizopus stolonoifer, Saccharomyces cerevisiae, and E. coli and its antibacterial stability in $24 \mathrm{~h}$.
\end{abstract}

Keywords: star anise; essential oil composition; hydroxypropyl- $\beta$-cyclodextrin; encapsulation; molecular modeling; volatilization stability; antibacterial properties

\section{Introduction}

Star anise (Illicium verum, Hooker $\mathrm{f}$.) belongs to the Magnoliaceae or Magnolia family. Its fruit is one of the most important spices, and it is indigenous to Southeastern China. Moreover, it has many beneficial functions due to its antioxidant [1], antibacterial, liver cancer preventative [2], and insecticidal characteristics [3]. Star anise essential oil (SAEO), which is extracted from star anise fruits, accounts for 3-3.5 wt.\% of fresh fruit and exceeds $8 \mathrm{wt.} \%$ of dried fruit by steam distillation [4]. SAEO is widely used in food and medicine because of its good biological activity [5]. It is extensively used in baked goods, confections, and alcoholic and soft drinks [6]. In addition, it can alleviate inflammatory responses [7] and is a common flavor in medicinal tea, cough mixtures, and pastilles.

In recent years, the spoilage microorganisms in food have become resistant to synthetic antimicrobial agents, which has aroused researcher's interest in the study of natural antimicrobial agents. Natural ingredients in many plants can kill or inhibit the growth of harmful microorganisms in food. There is an increased interest focusing on essential oils as alternative agents for the control of 
food corruption and harmful microbial reproduction [8-10]. A number of reports have demonstrated the antibacterial properties of the SAEO [11-13]. The antibacterial activities of SAEO are related to its bioactive volatile components. The main components obtained by steam distillation, specifically trans-anethole, estragole and limonene, account for about $96 \%$ of the total components [14].

Although the antibacterial properties of SAEO have been the target of much attention, the applications of SAEO are limited due to its high volatility, strong smell, and unstable physical and chemical properties [15-17]. The encapsulation techniques based on cyclodextrins (CDs) can solve this problem [18]. CDs and its derivatives can encapsulate essential oils and volatile compounds to stabilize their properties, extend their storage capabilities, mask the irritating smell [19], afford slow release properties [20,21] and enhance the antioxidant activity [22,23]. In addition, the main components of SAEO are volatile, and encapsulation can regulate their release, because the control of the release rate is the key of prolonging the antimicrobial characteristics of SAEO. Encapsulation of essential oil and its active constituents has been reported by several researchers. In 2014, the inclusion complexes of thymol and thyme essential oil with $\beta-C D$ were successfully prepared to validate that the complexes exhibited good antibacterial activity [24]. Furthermore, several researchers successfully encapsulated black pepper essential oil in hydroxypropyl- $\beta$-cyclodextrin (HPCD). The results exhibited a slight decrease in the oxidation resistance of the inclusion complexes, while the antibacterial activity of black pepper oil improved by four-fold against both S. aureus and E. coli due to a likely synergistic effect between the wall material and essential oil [25].

CDs are cyclic oligosaccharides, occurring in nature by bacterial degradation of starch. In these natural processes, CDs have six, seven, or eight glucose units linked by $\alpha-(1,4)$-glycosidic bonds, being named $\alpha-, \beta$-, and $\gamma$-cyclodextrin, respectively. CDs have a cyclic molecular space structure, and exhibit special spatial properties, specifically a hydrophobic endothecium and hydrophilic exothecium, in aqueous solutions. This property allows CDs to form an inclusion complex with appropriately-sized lipid-soluble molecules [26], thereby improving the water solubility, bioavailability, or stability of the encapsulated molecules. The sustained release of the inclusion compound reduces the volatile loss of the essential oil [27]. HPCD is a derivative of $\beta-C D$ and is introduced to the hydroxypropyl groups in the molecular structure of $\beta-C D$ to enhance its water solubility and toxicological properties. SAEO contains a variety of volatile components, such as terpenes, terpenoids and phenol-derived aromatic components, and the compositions are vital for their antimicrobial activities. Moreover, the encapsulation ability of HPCD is different toward a variety of components, which may affect the biological activity of SAEO. However, to our knowledge, few reports have focused on molecular modeling of selective encapsulation of SAEO by HPCD and changes of composition, volatility stability, and antibacterial activity of SAEO after HPCD encapsulation.

The present study investigates the effect of selective encapsulation of SAEO by HPCD on its components, volatility stability, and antibacterial activity. The component change after the SAEO encapsulated in HPCD was determined through a solvent extraction and GC-MS method, and the inclusion complex was characterized by FTIR and ${ }^{1} \mathrm{H}$ NMR. According to the principle of lowest energy, the structure of the host and guest after encapsulation was simulated by Hyperchem 8.0 issued by Hypercube, Inc. (Gainesville, FL, USA). The volatility stability of SAEO before and after encapsulation was described by electronic nose for the first time. Furthermore, the effect of HPCD's selective encapsulation of SAEO on its antibacterial properties was evaluated via the restraint of its in vitro microbial growth (i.e., Rhizopus stolonoifer, Saccharomyces cerevisiae, and E. coli).

\section{Results and Discussion}

\subsection{GC-MS Analyses}

The GC-MS analysis techniques are often employed to identify the components of essential oils [28]. The identification of a single compound is based on the retention time and mass spectrometry of the sample. The GC-MS analysis of the SAEO before and after encapsulation is presented in Table 1. 
It can be seen from the Table 1 that the compositions and relative contents of SAEO after encapsulating changed, which may affect its antibacterial properties. Thirteen of SAEO main components were identified by GC-MS, which represent $97.09 \% \pm 2.35 \%$ of all the components in SAEO (Table 1). The major components were identified as trans-anethole $(91.38 \% \pm 0.98 \%)$, estragole $(2.55 \% \pm 0.41 \%)$, and trans-foeniculin $(2.15 \% \pm 0.65 \%)$. This result is similar to that of Aly et al. [14], though the content of the compounds is slightly different.

Table 1. Composition analysis results of SAEO before (A) and after (B) the encapsulation ${ }^{1}$.

\begin{tabular}{|c|c|c|c|c|c|}
\hline No. & $\begin{array}{c}\text { Retention } \\
\text { Time (Min) }\end{array}$ & Compound & Structure & $\begin{array}{c}\text { Content in } \\
\text { Sample A (\%) }\end{array}$ & $\begin{array}{c}\text { Content in } \\
\text { Sample B (\%) }\end{array}$ \\
\hline 1 & 18.656 & Eucalyptol & & $0.12 \pm 0.06$ & $0.07 \pm 0.01$ \\
\hline 2 & 19.574 & $\begin{array}{l}\text { 1-Methyl-5-(1- } \\
\text { methylethenyl)-(R)- } \\
\text { cyclo-hexene }\end{array}$ & & $0.09 \pm 0.01$ & $0.04 \pm 0.00$ \\
\hline 3 & 19.759 & Estragole & & $2.55 \pm 0.41$ & $2.23 \pm 0.33$ \\
\hline 4 & 23.118 & cis-Anethole & & $0.12 \pm 0.05$ & $0.16 \pm 0.03$ \\
\hline 5 & 23.270 & $\begin{array}{l}\text { 2-Hydroxy-4-methyl- } \\
\text { benzaldehyde }\end{array}$ & & $0.08 \pm 0.01$ & -2 \\
\hline 6 & 25.243 & trans-Anethole & & $91.38 \pm 0.98$ & $95.36 \pm 1.09$ \\
\hline 7 & 25.724 & o-Allyloxytoluene & & $0.04 \pm 0.01$ & $0.01 \pm 0.00$ \\
\hline 8 & 33.042 & $\alpha$-Farnesene & & $0.08 \pm 0.02$ & $0.01 \pm 0.01$ \\
\hline 9 & 33.240 & Caryophyllene & & $0.14 \pm 0.05$ & $0.07 \pm 0.02$ \\
\hline 10 & 34.251 & trans- $\alpha$-Bergamote-ne & & $0.18 \pm 0.07$ & $0.11 \pm 0.03$ \\
\hline 11 & 35.693 & Salicylic acid & & $0.09 \pm 0.02$ & $0.02 \pm 0.01$ \\
\hline 12 & 44.487 & trans-Foeniculin & & $2.15 \pm 0.65$ & $0.91 \pm 0.40$ \\
\hline 13 & 54.351 & trans-Chalcone & & $0.08 \pm 0.01$ & $0.01 \pm 0.00$ \\
\hline & & Total & & $97.09 \pm 2.35$ & $99.00 \pm 1.93$ \\
\hline
\end{tabular}

${ }^{1}$ All tests were performed in triplicate and the results are expressed as the mean \pm standard deviation; ${ }^{2}$ "_" means not detected. 
During the extraction of the encapsulation complex, 12 components were identified, which constituted for $99.00 \% \pm 1.93 \%$ of the gross components. Among these components, the relative contents were dominated by trans-anethole $(95.36 \% \pm 1.09 \%)$, estragole $(2.23 \% \pm 0.33 \%)$, and trans-foeniculin $(0.91 \% \pm 0.40 \%)$. Furthermore, the main components of the SAEO were the same before and after encapsulation. One of components was not identified in the extract due to its low content. In addition, the relative contents of the other SAEO components were all declined observably, except for trans-anethole and cis-anethole, which indicates that the trans-anethole and cis-anethole are more likely to be encapsulated in HPCD. These changes may be due to the difference in structure and polarity of the different constituent molecules in the SAEO and selective encapsulation of HPCD. The encapsulation effect of the HPCD on the guest molecules may be closely related to the structure of the guest molecules. According to Table 1, the structures of the three guest molecules with relatively high contents were similar, i.e., an isoallyl (or allyl) is connected to the benzene ring and an ether bond is connected with the benzene on the side of the para-position. However, the group connected to the structure mentioned above in trans-foeniculin was much more complex than that in trans-anethole and estragole. Consequently, it was more difficult to enter the HPCD cavity and form clathrate, which may have resulted in the bad encapsulate effect observed on the HPCD of trans-foeniculin.

\subsection{FT-IR Spectra Studies}

The IR spectra can be used to identify and analyze the compounds by the vibrational and rotational transitions of the molecules. Changes in the IR absorption peaks of the host and guest molecules can provide important information regarding the formation of the encapsulation complexes. Figure 1 presents the infrared spectra of SAEO, the HPCD, and their encapsulation complex.

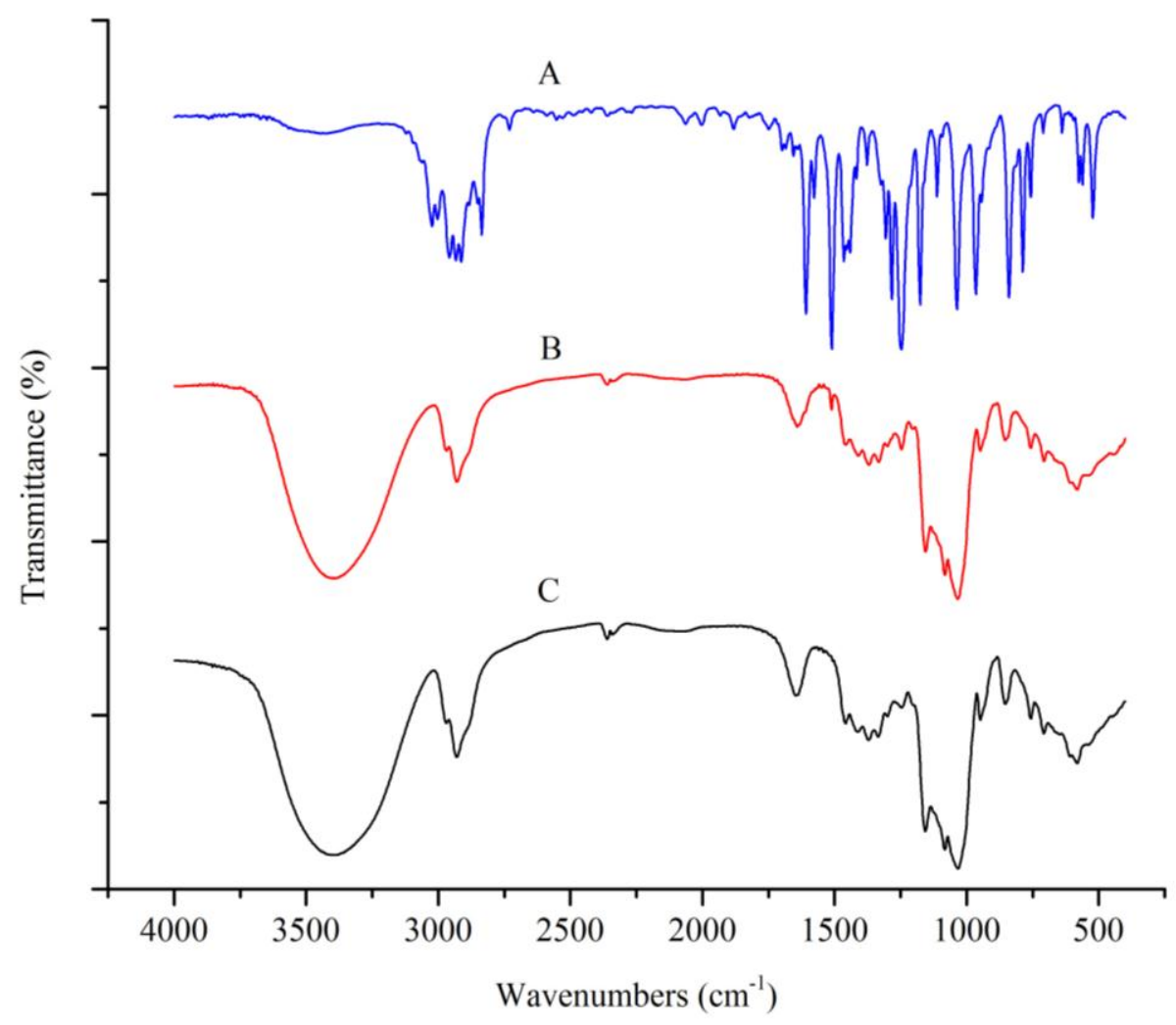

Figure 1. IR spectra of SAEO (A), HPCD (C) and their inclusion complex (B).

According to the IR spectra of the SAEO, very strong absorption peaks were observed at $3020 \mathrm{~cm}^{-1}$ and $3008 \mathrm{~cm}^{-1}$, which represent the $\mathrm{C}-\mathrm{H}$ stretching vibration peaks of the benzene ring and the $\mathrm{C}=\mathrm{C}$, respectively. The four sharp absorption peaks between $1609 \mathrm{~cm}^{-1}$ to $1447 \mathrm{~cm}^{-1}(1609,1507$, 
1464 , and $1447 \mathrm{~cm}^{-1}$ ) is defined by the stretching vibration peaks of the benzene ring framework. The stretching vibration peaks of C-O-C were represented by the peaks at 1248,1175 , and $1038 \mathrm{~cm}^{-1}$. The C-H bending vibration peaks of the substituent aromatics are represented by the peaks at $842 \mathrm{~cm}^{-1}$ and $790 \mathrm{~cm}^{-1}$. The relative content of trans-anethole in the SAEO was calculated to be $91.38 \% \pm 0.98 \%$. Therefore, the IR spectrum of the SAEO was very similar to the spectrum of trans-anethole [21]. The above information indicated that the molecules of the main constituents in the SAEO contained $\mathrm{C}=\mathrm{C}$ bonds and aromatic ether bonds. This inference was consistent with the above-mentioned GC-MS analytical results.

Figure 1 reveals that the IR spectrum of the complex is very similar to that of HPCD. In addition, some characteristic absorption peaks $\left(3020,1609\right.$, and $790 \mathrm{~cm}^{-1}$ ) of SAEO in the IR spectra of the inclusion complex were not identified. These bands are masked due to overlapping with the more intense bands of HPCD. However, the absorption peaks at 1507 and $1248 \mathrm{~cm}^{-1}$ exhibit a decrease in the intensity, whereas that at $842 \mathrm{~cm}^{-1}$ exhibits a slight shift due to the stretching vibration of C-O-C and the bending vibration of $\mathrm{C}-\mathrm{H}$ of the para-substituted benzene $[29,30]$. This could be explained by the stretching vibrations of the benzene framework and aromatic ether bond in the SAEO molecules being restricted following the formation of the inclusion and the low guest quantity in the inclusion complexes. The above information shows that the benzene ring and the aromatic ether bond in the SAEO molecules entered the cavity of the HPCD, and indirectly validates that some SAEO components were successfully encapsulated by the HPCD.

\section{3. ${ }^{1} \mathrm{H}$ NMR Spectra Analyses}

${ }^{1} \mathrm{H}$ NMR can provide valuable information about the spatial position of guest molecules in the cyclodextrin cavity, as well as the formation and dissociation encapsulation conditions in the solvent. $\mathrm{H} 3$ and $\mathrm{H} 5$ are atoms in the inner wall of the cyclodextrin cavity. When the guest molecules enter the cavity, the chemical shift of the $\mathrm{H} 3$ and $\mathrm{H} 5$ atoms in the cyclodextrin cavity changed due to the interaction between the guest molecule and the hydrophobic cavity of the cyclodextrins [31].

Figure 2 presents the ${ }^{1} \mathrm{H}$ NMR spectra of SAEO, the inclusion complex, and the HPCD. The ${ }^{1} \mathrm{H}$ NMR diagram of SAEO exhibited obvious proton peaks at 7.3 and $6.8 \mathrm{ppm}$, which indicates that the molecular structure of the compositions in SAEO contains a benzene ring. The proton peaks near 6.3 and $6.1 \mathrm{ppm}$ indicate the presence of a double bond in the molecular structure of the chemical composition of SAEO. The proton peaks near 3.3 and $3.7 \mathrm{ppm}$ symbolize that the SAEO molecular composition contains a C-O-C structure. The proton peak near $1.8 \mathrm{ppm}$ is a characteristic peak of $\mathrm{H}$ on the methyl or methylene structure linked to the double bond. These results were well in agreement with the analytical results of the GC-MS analysis. The ${ }^{1} \mathrm{H}$ NMR diagram of the encapsulation complex exhibited the presence of both HPCD and SAEO proton peaks. Figure 2B,C presents the chemical shift changes in the protons of the D-glucopyranose units in the HPCD molecules. No changes were observed in the H1 atoms in the mid-structure and H6 atoms at the outermost side of the HPCD cavity, whereas the $\mathrm{H} 2$ and $\mathrm{H} 4$ atoms outside the cavity shifted slightly towards the low field. The $\mathrm{H} 3$ atoms near the wider edge in the cavity visibly shifted towards the high field, and the $\mathrm{H} 5$ atoms in the depth of the cavity also exhibited a high field shift. Based on the ${ }^{1} \mathrm{H}$ NMR spectra analysis of the SAEO and the inclusion complex, the benzene ring structure and the double bond entered the cavity of HPCD. The stronger shielding effect of the benzene ring and the double bond resulted in an obvious increase in the electron cloud density around the $\mathrm{H} 3$ and $\mathrm{H} 5$ atoms and a decrease in the chemical shift. As a result, the $\mathrm{H} 3$ and $\mathrm{H} 5$ atoms shifted towards the high field. These changes indicate that the inclusion complex has been successfully formed. 


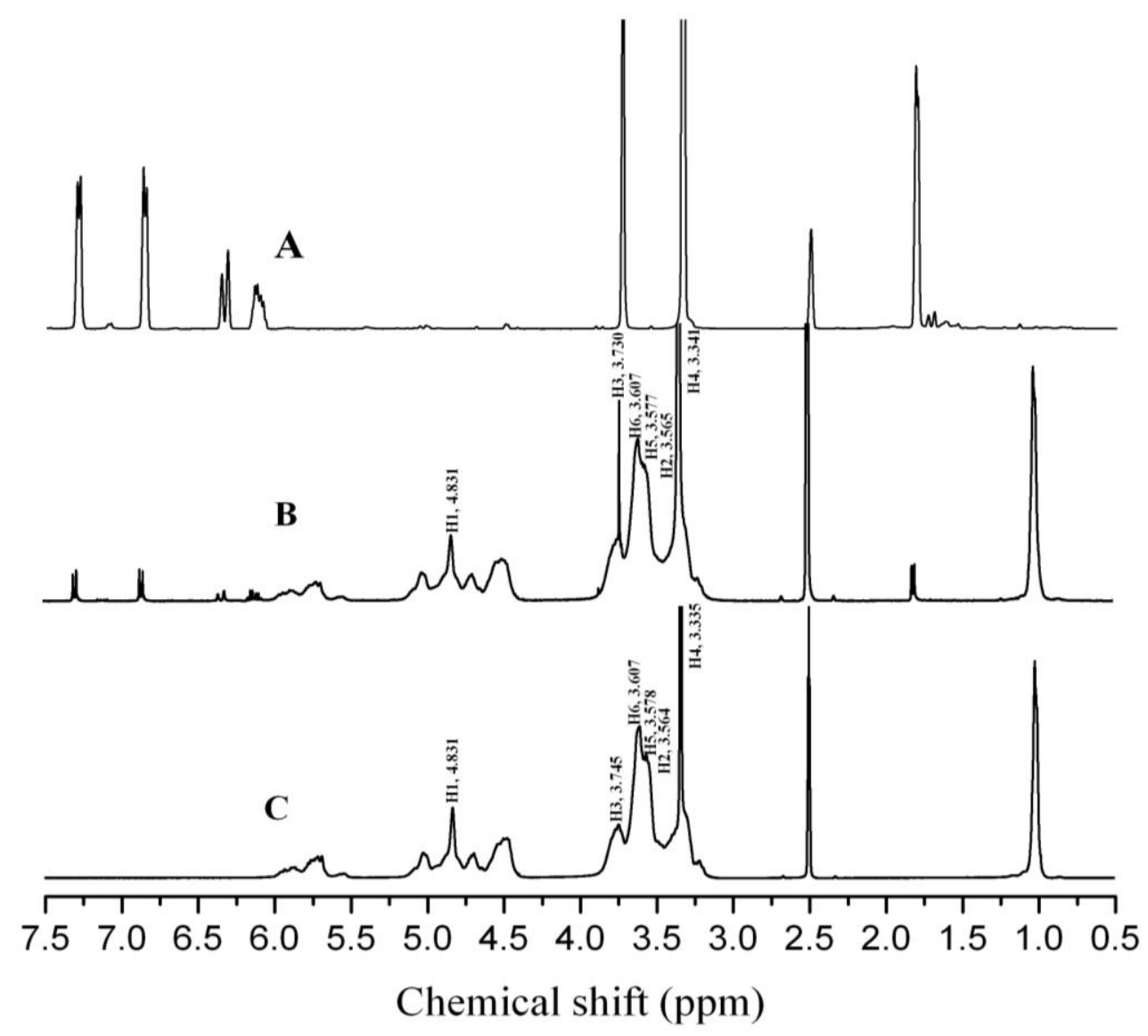

Figure 2. ${ }^{1} \mathrm{H}$ NMR spectra of SAEO (A), the inclusion complex (B), and HPCD (C).

\subsection{Molecular Modeling Studies}

At present, molecular modeling based on molecular mechanics is been widely applied to characterize the three-dimensional structure of inclusion complexes with cyclodextrins [32]. The above results indicate that the main components of SAEO in the encapsulation compound were trans-anethole, estragole, and trans-foeniculin, of which the possible molecular models and corresponding three-dimensional encapsulation structures were generated according to the PM3 method of Hyperchem 8.0. The models of the three types of inclusion complexes obtained by the methods in Section 3.6 are presented in Figure 3. The $\Delta \mathrm{E}$ of model A $(1.595 \mathrm{kcal} / \mathrm{mol})$ of the trans-anethole molecule was positive and was significantly higher than that of model $\mathrm{B}$ $(-9.067 \mathrm{kcal} / \mathrm{mol})$ given that the encapsulating process reduced the energy of the CDs. As a result, it is unreasonable to generate model $\mathrm{A}$ of the trans-anethole molecule. The $\Delta \mathrm{E}$ of model B $(-7.881 \mathrm{kcal} / \mathrm{mol})$ was slightly lower than that of model A $(-7.323 \mathrm{kcal} / \mathrm{mol})$ of the estragole molecule. The $\Delta \mathrm{E}$ of model B $(-14.583 \mathrm{kcal} / \mathrm{mol})$ was significantly lower than that of model A $(-1.973 \mathrm{kcal} / \mathrm{mol})$ of the trans-foeniculin. Therefore, model B of the three guest molecules exhibited the most reasonable inclusion complex structure. Figure 3(B1-B3) indicates that all three guest molecules were inserted into the cavity of HPCD of the isoallyl (or allyl) side. Moreover, the isoallyl (or allyl) group was deeply inserted, and the benzene ring was observed near the wide edge of the HPCD, whereas the ether bonds were exposed outside the HPCD cavity. The formation of the inclusion complex was largely a result of the addition of the benzene ring of the three molecules to the hydrophobic HPCD cavity by hydrogen bonding, which is consistent with the analysis results of FT-IR and ${ }^{1} \mathrm{H}$ NMR. 

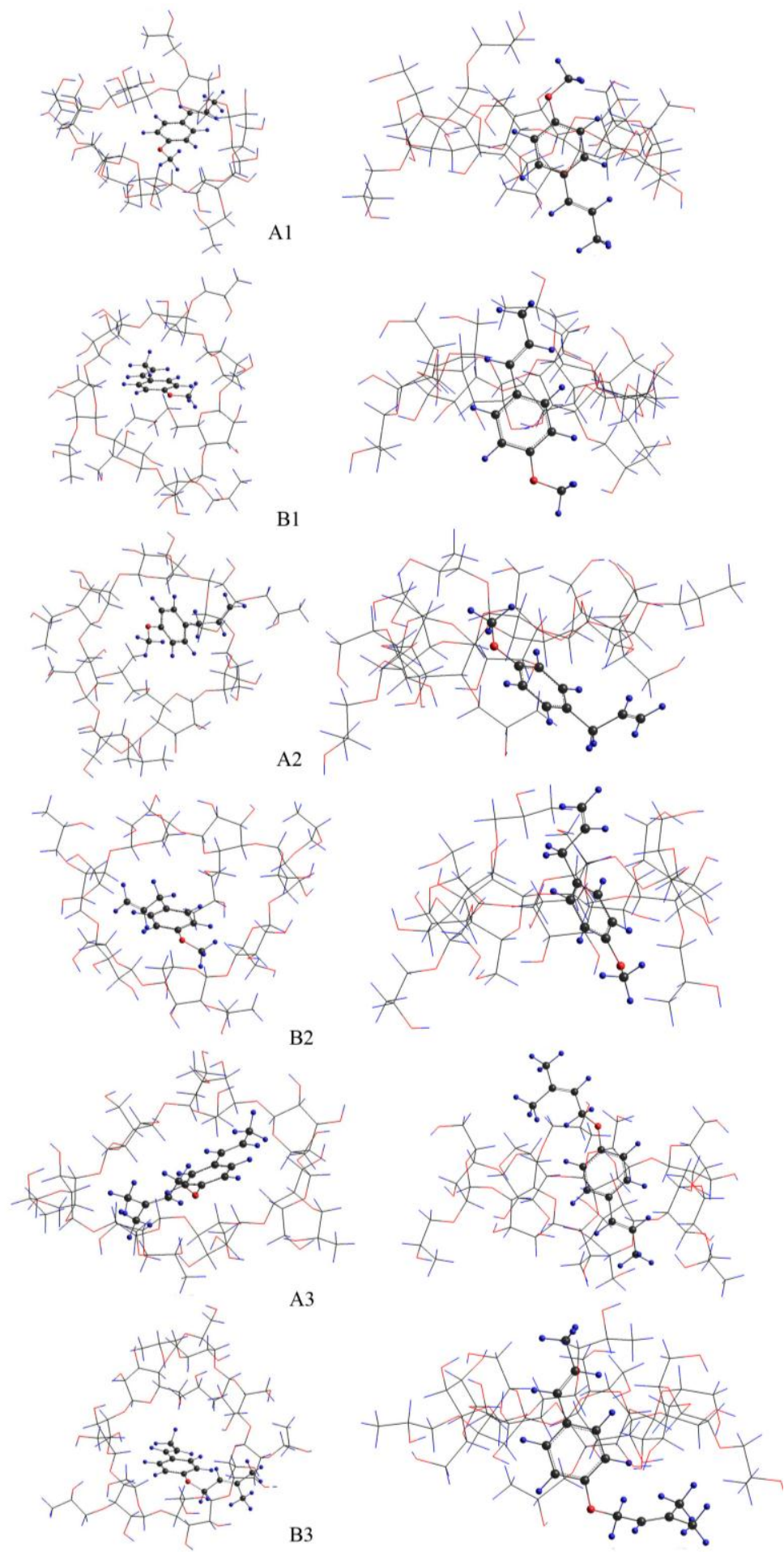

Figure 3. Energy-minimized modes obtained by the PM3 calculations for the complex of trans-anethole (A1 and B1), estragole (A2 and B2), and trans-foeniculin (A3 and B3) with HPCD. Left, top view; right, side view.

\subsection{Volatile Stability}

SAEO contains a large number of volatile components with a strong smell, and that volatile losses may affect its antibacterial activity, and the pungent smell will limit its application in food preservation. This volatile loss can be effectively reduced after encapsulating SAEO to HPCD, while masking this pungent smell without diminishing its biological activity [25]. Electronic nose technology is 
an artificial intelligence technology that simulates the human sense of smell, and is widely used in quality analysis and classification of essential oils [33]. The results of the comparison of volatile stability of SAEO, inclusion complex, and HPCD are shown in Figure 4. Figure 4A shows that the volatile components in the emulsion of SAEO and inclusion complex were sensitive to sensors no. 2, no. 7, and no. 9. The sensors no. 2, no. 7, and no. 9 indicate "broad range", "sulfur-organic" and "sulf-chlor", respectively. The electronic nose describes the smell characteristics of SAEO as "sulfur-organic" and "sulf-chlor", which may be related to its strong volatile irritation. It is also shows from Figure 4A that there is a difference in the shape of the smell radar map of the SAEO and clathrate. This result corroborates the "changes in the composition and content of SAEO after the HPCD encapsulation" analyzed by the GC-MS analysis. The signal values detected by no. 7 and no. 9 sensors in Figure 4B shows that the "sulfur-organic" and "sulf-chlor" smell of the emulsion of SAEO was significantly stronger than that of the encapsulation solution. This indicates that the embedding of HPCD masks the partial irritating smell of SAEO, which makes the encapsulation compound have a sustained release effect.

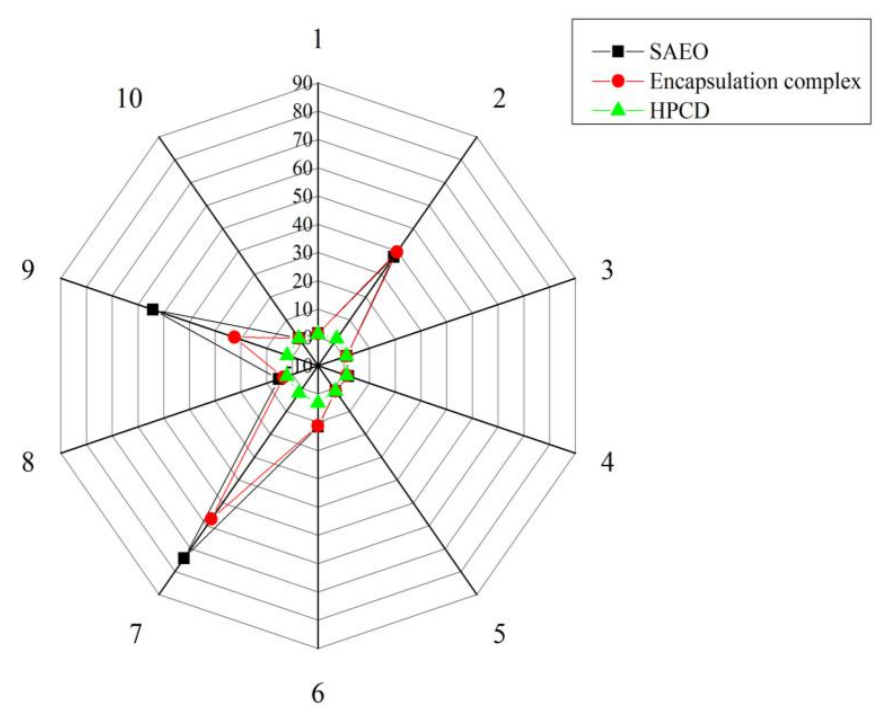

A

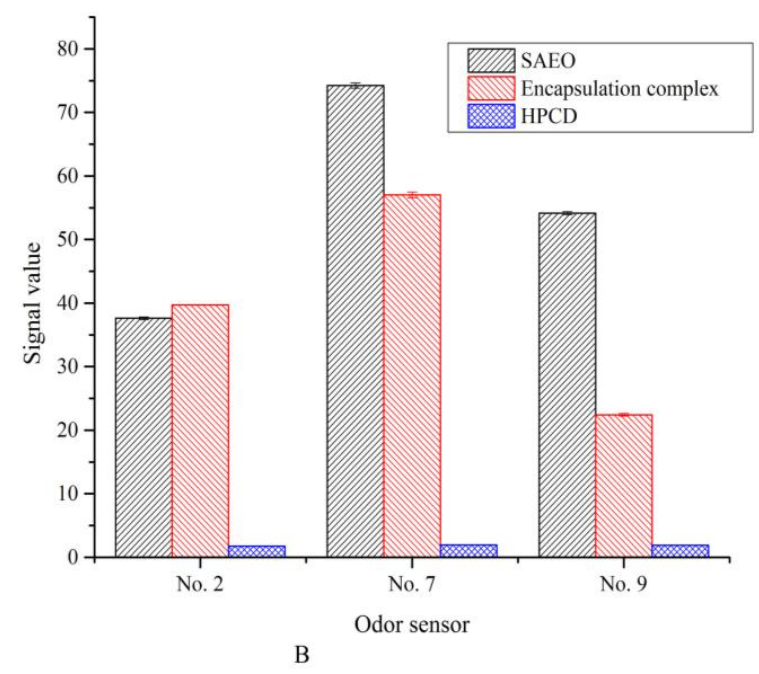

Figure 4. Analysis results of volatile stability of SAEO, the encapsulation complex and HPCD: (A) radar-plot detected using 10 sensors; (B) bar-plot based on responses of relatively sensitive sensors No. 2, 7 and 9. 


\subsection{In Vitro Antimicrobial Activity}

According to the previous literature, SAEO is beneficial in its ability to inhibit microorganism growth [34]. However, its instability and strong volatility challenges its widespread application in food preservation. The present study described the capsulation method of SAEO to the HPCD cavity, of which the restraining effects on Rhizopus stolonoifer, Saccharomyces cerevisiae, and E. coli before and after encapsulation were compared. According to Table 2 and Figure 5, SAEO and the inclusion complex had inhibitory effects on Rhizopus stolonoifer, Saccharomyces cerevisiae, and E. coli, the inhibition effect against Rhizopus stolonoifer was better than that of Saccharomyces cerevisiae and E. coli, which is consistent with the reported results in the literature [12]. In addition, under the same concentration, the antibacterial effect of the clathrate was obviously better than that of the free SAEO. It is possible that the relative content of trans-anethole, the main antibacterial component of encapsulated SAEO, increased (from $91.38 \%$ to $95.36 \%$ ) due to the encapsulation selectivity of HPCD. Moreover, the encapsulation by HPCD improved the water solubility of SAEO so that the antibacterial components in SAEO can more easily penetrate the cell membrane of microorganism, thereby exerting the inhibitory effect. Figure 5 also shows that the antibacterial stability of the inclusion complex was better than that of the free SAEO in $24 \mathrm{~h}$, especially at two concentrations of $5.400 \times 10^{-2} \mathrm{mmol} / \mathrm{mL}$ and $0.108 \mathrm{mmol} / \mathrm{mL}$, which may be due to the encapsulation slowing the release of SAEO.
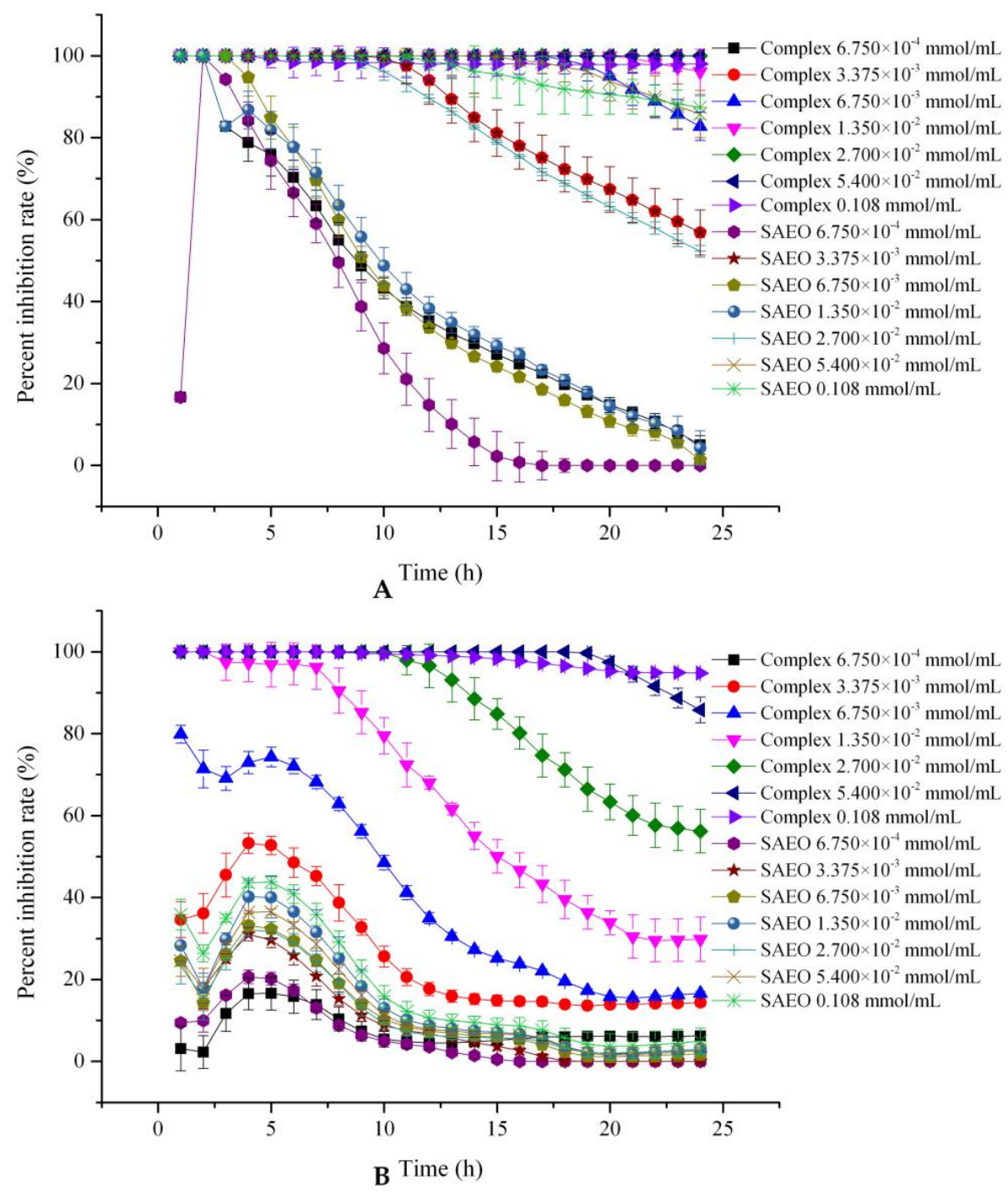

Figure 5. Cont. 


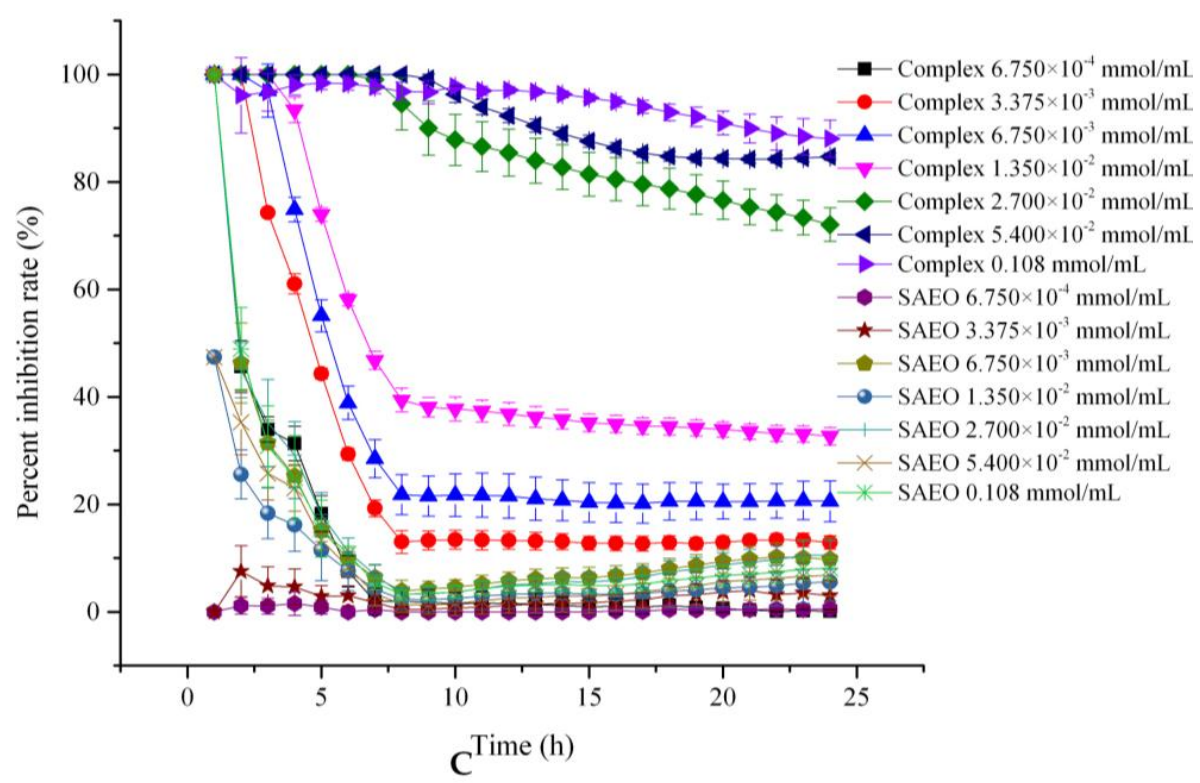

Figure 5. The inhibition effect of SAEO and the inclusion complex with HPCD on Rhizopus stolonoifer (A); Saccharomyces cerevisiae (B) and E. coli (C).

Table 2. The minimum inhibitory concentrations (MICs) of SAEO and the inclusion complex on Rhizopus stolonoifer, Saccharomyces cerevisiae, and E. coli.

\begin{tabular}{cccc}
\hline \multirow{2}{*}{ Antibacterial Agents } & \multicolumn{3}{c}{ MICs (mg/mL) } \\
\cline { 2 - 4 } & Rhizopus stolonoifer & Saccharomyces cerevisiae & E. coli \\
\hline SAEO & 20 & $>20^{1}$ & $>20$ \\
Iclusion complex ${ }^{2}$ & 2.5 & 20 & 20
\end{tabular}

\footnotetext{
${ }^{1}$ Values preceded by a greater than symbol (>) means that tested concentrations were not sufficient to determine the MIC values; ${ }^{2}$ Values are based on the actual concentrations of SAEO encapsulated in the HPCD (calculated from encapsulation efficiency).
}

\section{Materials and Methods}

\subsection{Materials}

Star anise was purchased from Guangxi Rongxian Guoyao Agricultural Products Co., Ltd. (Yulin, China) and underwent the hydrodistillation method to generate SAEO and was dried with anhydrous sodium sulfate. HPCD (purity $>99 \%$, average Mw = 1380) was purchased from Sigma-Aldrich Shanghai Trading Co. Ltd. (Shanghai, China). Rhizopus stolonoifer (separated from baked food), Saccharomyces cerevisiae, and E. coli were provided by the microbial laboratory in the Anyang Institute of Technology. Sabouraud dextrose broth (SDB) and tryptic soy broth (TSB) were purchased from Qingdao High Tech Industrial Park Hopebio Technology Co., Ltd. (Qingdao, China). Other reagents were of analytical grade. The water used was double-distilled and deionized.

\subsection{Preparation of the Inclusion Complex of SAEO with HPCD}

The SAEO inclusion complexes were prepared by the freeze-drying method according to the published procedure [35]. SAEO was added to $25 \mathrm{~mL} \mathrm{HPCD}$ aqueous solution with the mole ratio of 1:1. The mixture was ultrasonically treated and magnetically stirred for $96 \mathrm{~h}$ at $30{ }^{\circ} \mathrm{C}$ in the dark. The encapsulation solution was filtered through $0.45 \mu \mathrm{m}$ filters to eliminate any undissolved compounds after the complexation reaction. The filtrates were lyophilized at $-60{ }^{\circ} \mathrm{C}$ and $100 \mathrm{~Pa}$ in a Millrock Technology BT85 freeze dryer (Millrock Technology, Inc., Kingston, NY, USA). 


\subsection{GC-MS Analyses}

SAEO was accurately weighed and dissolved in n-hexane to prepare sample solution A at a concentration of $0.003 \mathrm{mg} / \mathrm{mL}$. Ten milligrams of SAEO/HPCD encapsulation compound was accurately weighed and dissolved in $5 \mathrm{~mL}$ deionized water, after which $10 \mathrm{~mL}$ n-hexane was added. The sample underwent ultrasonic extraction for $10 \mathrm{~min}$ to prepare sample solution $\mathrm{B}$. The constituents of SAEO before (sample solution A) [36] and after (sample solution B) encapsulation were analyzed by GC-MS (Agilent 7890A-5975C, Santa Clara, CA, USA).

The GC conditions are presented as follows: J and W 122-5532 quartz capillary column $(30 \mathrm{~m} \times 250 \mu \mathrm{m} \times 0.25 \mu \mathrm{m})$; an inlet temperature of $250{ }^{\circ} \mathrm{C}$; oven temperature was maintained at $60{ }^{\circ} \mathrm{C}$ for $1 \mathrm{~min}$, after which it was elevated by $2{ }^{\circ} \mathrm{C} / \mathrm{min}$ to $130^{\circ} \mathrm{C}$ and subsequently elevated by $5{ }^{\circ} \mathrm{C} / \mathrm{min}$ to $240{ }^{\circ} \mathrm{C}$, at which the temperature was maintained for $1 \mathrm{~min}$; a split ratio of $15: 1$; carrier gas $(99.999 \% \mathrm{He})$; a velocity of $0.95 \mathrm{~mL} / \mathrm{min}$; and an injection volume of $1 \mu \mathrm{L}$. The MS conditions are presented as follows: electron impact (EI) ion source; an ion source temperature of $230{ }^{\circ} \mathrm{C}$; an MS quadrupole temperature of $150{ }^{\circ} \mathrm{C}$; and a mass scan range of 30-500 amu.

\subsection{FT-IR Spectra}

Approximately $1 \mathrm{mg}$ HPCD and $1 \mathrm{mg}$ of the inclusion complex samples were placed in an agate mortar with about $100 \mathrm{mg}$ dry potassium bromide to form a fine powder, respectively. The sample was then mixed well, loaded into a mold, pressed into tablets, and placed in the Bruker Tensor II FT-IR spectrometer (Karlsruhe, Germany) for testing, respectively. The SAEO tablet sample was prepared by adding a drop of SAEO to the potassium bromide tablet.

\section{5. ${ }^{1} H$ NMR Spectra}

The ${ }^{1} \mathrm{H}$ NMR spectra were recorded at $25^{\circ} \mathrm{C}$ with a Bruker AM-400 NMR spectrometer (Karlsruhe, Germany) at $500 \mathrm{MHz}$. SAEO, the encapsulation complex, and HPCD were dissolved in the DMSO solution, placed in NMR tubes with $5 \mathrm{~mm}$ inner diameters, and respectively tested.

\subsection{Molecular Modeling}

According to the above-mentioned test method in Section 3.3, the main constituents in SAEO before and after encapsulation were trans-anethole, estragole, and trans-foeniculin. Trans-anethole, estragole, trans-foeniculin, and HPCD were molecularly simulated using Hyperchem 8.0 issued by Hypercube, Inc. (Gainesville, FL, USA). The structures of trans-anethole, estragole, trans-foeniculin and HPCD were first constructed by means of Hyperchem 8.0 and then optimized by the PM3 method. The ether linkage side or isoallyl (or allyl) of the guest molecules were then inserted into the cavity of HPCD from the wide edge to the structure model A or model B, respectively. Both modes were minimized with the conjugate gradient optimizer until a root mean square (RMS) value of $0.01 \mathrm{kcal} /(\mathrm{mol} \AA)$ was obtained [37]. The $\Delta \mathrm{E}$ of the minimum energy mode was calculated on the Equation (1):

$$
\Delta E=E_{\text {complex }}-\left(E_{\text {host }}+E_{\text {guest }}\right)
$$

where $E_{\text {host }}, E_{\text {guest }}$, and $E_{\text {complex }}(\mathrm{kcal} / \mathrm{mol})$ represent the calculated energy of the HPCD, the main components' molecules in the SAEO, and the encapsulation molecular complex, respectively.

\subsection{Volatile Stability}

The ratio of the resistance (G/G0) of the volatile gas in the sample to the blank was obtained by the 10 gas sensors of the PEN3 electronic nose (Schwerin, Germany), in order to describe the volatile stability of the sample. That is, the smaller the ratio, the better the volatility stability. Twelve milligrams of SAEO and the encapsulation complex containing the same amount of SAEO were added to the sample bottle with $5 \mathrm{~mL}$ deionized water, respectively. Their volatility stability data were detected by 10 gas sensors of PEN3 electronic nose after standing for $30 \mathrm{~min}$ at room temperature. The same 
method was used to detect the volatility stability of HPCD. All the test samples were performed in triplicate.

\subsection{In Vitro Antimicrobial Activity}

Antimicrobial activity and the MICs analyses of free and encapsulated SAEO were performed against Rhizopus stolonoifer, Saccharomyces cerevisiae, and E. coli (provided by the microbial laboratory in the Anyang Institute of Technology) in 96-well microtiter plates by several researchers with minor modification $[25,38,39]$. These strains representing typical spoilage organisms commonly exist in food products. Rhizopus stolonoifer and Saccharomyces cerevisiae were cultured on SDB at $28^{\circ} \mathrm{C}$, and E. coli was cultured on TSB at $37{ }^{\circ} \mathrm{C}$. The suspensions with strains (Rhizopus stolonoifer, Saccharomyces cerevisiae, and E. coli) concentration of approximately $10^{5} \mathrm{CFU} / \mathrm{mL}$ were prepared and $1 \mathrm{~mL}$ of the bacterial suspension was added to $150 \mathrm{~mL}$ of liquid medium. Three-hundred microliters of inoculated culture medium was added to each well of the microplate. Furthermore, $0.000,6.750 \times 10^{-4}$, $3.375 \times 10^{-3}, 6.750 \times 10^{-3}, 1.350 \times 10^{-2}, 2.700 \times 10^{-2}, 5.400 \times 10^{-2}$, and $0.108 \mathrm{mmol} / \mathrm{mL} \mathrm{SAEO}$ and the inclusion complex containing the same amount of SAEO were added to the inoculated culture medium, respectively. That is, the concentrations of SAEO in the inoculated liquid medium containing inclusion complex are also $0.000,6.750 \times 10^{-4}, 3.375 \times 10^{-3}, 6.750 \times 10^{-3}, 1.350 \times 10^{-2}, 2.700 \times 10^{-2}$, $5.400 \times 10^{-2}$, and $0.108 \mathrm{mmol} / \mathrm{mL}$, respectively. The culture medium solution was mixed by a vortex oscillator to ensure good distribution. Incubations of Rhizopus stolonoifer and Saccharomyces cerevisiae were carried out in a dark room at $28{ }^{\circ} \mathrm{C}$ for $24 \mathrm{~h}$, and the incubation of $E$. coli was performed at $37^{\circ} \mathrm{C}$ for $24 \mathrm{~h}$. The OD value of liquid culture medium containing inoculums was then measured at $600 \mathrm{~nm}$ once every $1 \mathrm{~h}$ by a Bioscreen $\mathrm{C}$ automatic analyzer for microbial growth curves (Turku, Finland), respectively. The inhibition rate was calculated on the Equation (2). Each test was performed in triplicate:

$$
\text { Inhibition rate }(\%)=\frac{\Delta O D_{C}-\Delta O D_{S}}{\Delta O D_{C}} \times 100 \%
$$

where $\triangle O D_{C}$ and $\triangle O D_{S}$ are the value change of the control sample and the post-treatment samples with SAEO or the SAEO/HPCD inclusion complex at OD of $600 \mathrm{~nm}$ after a certain period of incubation time, respectively.

The MICs of free and encapsulated SAEO were determined using a microdilution assay [25]. The antimicrobial inclusion complexes were added to the microtiter plates as aqueous suspensions, while the SAEO was added as aqueous microemulsions. The concentration of inclusion complexes added to the test wells ranged from 62.5 to $1000 \mathrm{mg} / \mathrm{mL}$ (equivalent to $1.25-20 \mathrm{mg} / \mathrm{mL}$ of SAEO concentration based on the entrapment efficiency), while the concentration of free SAEO ranged from 1.25 to $20 \mathrm{mg} / \mathrm{mL}$.

Negative control wells were prepared with sterile culture medium containing tested samples (free and encapsulated SAEO). Positive control wells were prepared with microbial suspension inoculating in culture medium. The microplates were incubated at $37^{\circ} \mathrm{C}$ or $28^{\circ} \mathrm{C}$ for $24 \mathrm{~h}$ and the turbidity was determined at $600 \mathrm{~nm}$. The MICs of free and encapsulated SAEO were recorded as the lowest concentration where no visible growth $\left(\leq 0.05\right.$ changed in $\left.O D_{600}\right)$ was observed in the wells after $24 \mathrm{~h}$ of incubation.

\section{Conclusions}

The present study investigated the characteristics of SAEO after encapsulation in HPCD. The results of the FT-IR and ${ }^{1} \mathrm{H}$ NMR spectra confirmed that SAEO was successfully encapsulated in the HPCD cavity. Hydrophobic SAEO became a water-soluble encapsulation complex. However, the compositions of SAEO and its relative content were different from those before encapsulation. In addition to cis-anethole and trans-anethole, the relative content of most components decreased. The components that contained an ether bond were more easily encapsulated into the HPCD cavity as compared to the other components, which may result in changes in the antimicrobial properties 
of SAEO. The results of the molecular modeling indicated that the embedded modes of the three main components were inserted into the cavity of HPCD on the isoallyl (or allyl) side. In addition, the components with higher contents formed complexes with HPCD more easily. The volatile stability of SAEO after encapsulation was evaluated by electronic nose, and the data showed that the "sulfur-organic" and "sulf-chlor" smell of the encapsulation solution was significantly lower than the SAEO and water mixture due to the embedding effect of the HPCD. This indicated that encapsulation significantly reduced the irritating smell of SAEO and makes the clathrate have a sustained release effect. The results of the antibacterial test indicated that the inhibitory effect of SAEO on Rhizopus stolonoifer, Saccharomyces cerevisiae, and E. coli markedly increased following the formation of the encapsulation complex due to the improvement of water solubility of SAEO. Furthermore, the antibacterial stability of the inclusion complex in $24 \mathrm{~h}$ was generally superior to that of free SAEO on account of the encapsulated slow release effect.

Author Contributions: C.Y. and Y.S conceived and designed the experiments; G.Z. performed the experiments; G.Z. and C.Y. analyzed the data; and G.Z. and C.Y. wrote the paper. All authors read and approved the final manuscript.

Acknowledgments: This work was supported by the National Science Foundation of China (grant number 31571881) and the National Natural Science Foundation of China (grant number 3127 1861).

Conflicts of Interest: The authors declare no competing interests.

\section{References}

1. Padmashree, A.; Roopa, N.; Semwal, A.D.; Sharma, G.K.; Agathian, G.; Bawa, A.S. Star-anise (Illicium verum) and black caraway (Carum nigrum) as natural antioxidants. Food Chem. 2007, 104, 59-66. [CrossRef]

2. Yadav, A.S.; Bhatnagar, D. Chemo-preventive effect of Star anise in $N$-nitrosodiethylamine initiated and phenobarbital promoted hepato-carcinogenesis. Chem.-Biol. Interact. 2007, 169, 207-214. [CrossRef] [PubMed]

3. Park, C.G.; Shin, E.; Kim, J. Insecticidal activities of essential oils, Gaultheria fragrantissima and Illicium verum, their components and analogs against Callosobruchus chinensis adults. J. Asia-Pac. Entomol. 2016, 19, 269-273. [CrossRef]

4. George, C.K. 24-Star anise A2. In Handbook of Herbs and Spices, 2nd ed.; Peter, K.V., Ed.; Woodhead Publishing: Cambridge, UK, 2012; pp. 487-503.

5. Chouksey, D.; Sharma, P.; Pawar, R.S. Biological activities and chemical constituents of Illicium verum hook fruits (Chinese star anise). Pharm. Sin. 2010, 1, 1-10.

6. Ize-Ludlow, D.; Ragone, S.; Bruck, I.S.; Bernstein, J.N.; Duchowny, M.; Pena, B.M.G. Neurotoxicities in Infants Seen with the Consumption of Star anise Tea. Jpn. J. Appl. Phys. 2004, 114, e653-e656. [CrossRef] [PubMed]

7. Kang, P.; Kim, K.Y.; Lee, H.S.; Min, S.S.; Seol, G.H. Anti-inflammatory effects of anethole in lipopolysaccharide-induced acute lung injury in mice. Life Sci. 2013, 93, 955-961. [CrossRef] [PubMed]

8. Alencar Filho, J.M.T.D.; Araújo, L.D.C.; Oliveira, A.P.; Guimarães, A.L.; Pacheco, A.G.M.; Silva, F.S.; Cavalcanti, L.S.; Lucchese, A.M.; Almeida, J.R.G.D.; Araújo, E.C.D.C. Chemical composition and antibacterial activity of essential oil from leaves of Croton heliotropiifolius in different seasons of the year. Rev. Bras. Farmacogn. 2017, 27, 440-444. [CrossRef]

9. El Hamdaoui, A.; Msanda, F.; Boubaker, H.; Leach, D.; Bombarda, I.; Vanloot, P.; El Aouad, N.; Abbad, A.; Boudyach, E.H.; Achemchem, F.; et al. Essential oil composition, antioxidant and antibacterial activities of wild and cultivated Lavandula mairei Humbert. Biochem. Syst. Ecol. 2018, 76, 1-7. [CrossRef]

10. Hąc-Wydro, K.; Flasiński, M.; Romańczuk, K. Essential oils as food eco-preservatives: Model system studies on the effect of temperature on limonene antibacterial activity. Food Chem. 2017, 235, 127-135. [CrossRef] [PubMed]

11. Rocha, L.; Candido Tietbohl, L.A. Chapter 85-Star anise (Illicium verum Hook) Oils A2. In Essential Oils in Food Preservation, Flavor and Safety; Preedy, V.R., Ed.; Academic Press: San Diego, CA, USA, 2016; pp. 751-756.

12. Singh, G.; Maurya, S.; DeLampasona, M.P.; Catalan, C. Chemical constituents, antimicrobial investigations and antioxidative potential of volatile oil and acetone extract of Star anise fruits. J. Sci. Food Agric. 2006, 86, 111-121. [CrossRef] 
13. Sultanbawa, Y. Chapter 23-Anise myrtle (Syzygium anisatum) Oils A2. In Essential Oils in Food Preservation, Flavor and Safety; Preedy, V.R., Ed.; Academic Press: San Diego, CA, USA, 2016; pp. 215-219.

14. Aly, S.E.; Sabry, B.A.; Shaheen, M.S.; Hathout, A.S. Assessment of antimycotoxigenic and antioxidant activity of Star anise (Illicium verum) In Vitro. J. Saudi Soc. Agric. Sci. 2016, 15, 20-27. [CrossRef]

15. Higueras, L.; López-Carballo, G.; Hernández-Muñoz, P.; Catalá, R.; Gavara, R. Antimicrobial packaging of chicken fillets based on the release of carvacrol from chitosan/cyclodextrin films. Int. J. Food Microbiol. 2014, 188C, 53-59. [CrossRef] [PubMed]

16. Abarca, R.L.; Rodríguez, F.J.; Guarda, A.; Galotto, M.J.; Bruna, J. Characterization of beta-cyclodextrin inclusion complexes containing an essential oil component. Food Chem. 2016, 196, 968-975. [CrossRef] [PubMed]

17. Wen, P.; Zhu, D.H.; Wu, H.; Zong, M.H.; Jing, Y.R.; Han, S.Y. Encapsulation of cinnamon essential oil in electrospun nanofibrous film for active food packaging. Food Control 2016, 59, 366-376. [CrossRef]

18. Ciobanu, A.; Mallard, I.; Landy, D.; Brabie, G.; Nistor, D.; Fourmentin, S. Retention of aroma compounds from Mentha piperita essential oil by cyclodextrins and crosslinked cyclodextrin polymers. Food Chem. 2013, 138, 291-297. [CrossRef] [PubMed]

19. Kfoury, M.; Hădărugă, N.G.; Hădărugă, D.I.; Fourmentin, S. Cyclodextrins as encapsulation material for flavors and aroma. In Encapsulations; Elsevier: New York, NY, USA, 2016; pp. 127-192.

20. Kfoury, M.; Auezova, L.; Greige-Gerges, H.L.N.; Fourmentin, S. Promising applications of cyclodextrins in food: Improvement of essential oils retention, controlled release and antiradical activity. Carbohydr. Polym. 2015, 131, 264-272. [CrossRef] [PubMed]

21. Zhang, W.; Li, X.; Yu, T.; Yuan, L.; Rao, G.; Li, D.; Mu, C. Preparation, physicochemical characterization and release behavior of the inclusion complex of trans-anethole and $\beta$-cyclodextrin. Food Res. Int. 2015, 74, 55-62. [CrossRef] [PubMed]

22. Costa, P.C.; Medronho, B.; Gon Alves, S.; Romano, A. Cyclodextrins enhance the antioxidant activity of essential oils from three Lamiaceae species. Ind. Crops Prod. 2015, 70, 341-346. [CrossRef]

23. Liu, H.; Yang, G.; Tang, Y.; Cao, D.; Qi, T.; Qi, Y.; Fan, G. Physicochemical characterization and pharmacokinetics evaluation of $\beta$-caryophyllene/ $\beta$-cyclodextrin inclusion complex. Int. J. Pharm. 2013, 450, 304-310. [CrossRef] [PubMed]

24. Tao, F.; Hill, L.E.; Peng, Y.; Gomes, C.L. Synthesis and characterization of $\beta$-cyclodextrin inclusion complexes of thymol and thyme oil for antimicrobial delivery applications. LWT Food Sci. Technol. 2014, 59, 247-255. [CrossRef]

25. Rakmai, J.; Cheirsilp, B.; Mejuto, J.C.; Torrado-Agrasar, A.; Simal-G Ndara, J.S. Physico-chemical characterization and evaluation of bio-efficacies of black pepper essential oil encapsulated in hydroxypropyl-beta-cyclodextrin. Food Hydrocoll. 2017, 65, 157-164. [CrossRef]

26. Pinho, E.; Grootveld, M.; Soares, G.; Henriques, M. Cyclodextrin-based hydrogels toward improved wound dressings. Crit. Rev. Biotechnol. 2014, 34, 328-337. [CrossRef] [PubMed]

27. Loftsson, T.; Duchêne, D. Cyclodextrins and their pharmaceutical applications. Int. J. Pharm. 2007, 329, 1-11. [CrossRef] [PubMed]

28. Li, Y.; Kong, D.; Wu, H. Analysis and evaluation of essential oil components of cinnamon barks using GC-MS and FTIR spectroscopy. Ind. Crops Prod. 2013, 41, 269-278. [CrossRef]

29. Kfoury, M.; Auezova, L.; Greige-Gerges, H.L.N.; Ruellan, S.; Fourmentin, S. Cyclodextrin, an efficient tool for trans-anethole encapsulation: Chromatographic, spectroscopic, thermal and structural studies. Food Chem. 2014, 164, 454-461. [CrossRef] [PubMed]

30. Kfoury, M.; Auezova, L.; Ruellan, S.; Greige-Gerges, H.L.N.; Fourmentin, S. Complexation of estragole as pure compound and as main component of basil and tarragon essential oils with cyclodextrins. Carbohydr. Polym. 2015, 118, 156-164. [CrossRef] [PubMed]

31. Aksamija, A.; Polidori, A.; Plasson, R.L.; Dangles, O.; Tomao, V.R. The inclusion complex of rosmarinic acid into beta-cyclodextrin: A thermodynamic and structural analysis by NMR and capillary electrophoresis. Food Chem. 2016, 208, 258-263. [CrossRef] [PubMed]

32. Sapte, S.; Pore, Y. Inclusion complexes of cefuroxime axetil with $\beta$-cyclodextrin: Physicochemical characterization, molecular modeling and effect of 1 -arginine on complexation. J. Pharm. Anal. 2016, 6, 300-306. [CrossRef] [PubMed] 
33. Gorji-Chakespari, A.; Nikbakht, A.M.; Sefidkon, F.; Ghasemi-Varnamkhasti, M.; Valero, E.L. Classification of essential oil composition in Rosa damascena Mill. genotypes using an electronic nose. J. Appl. Res. Med. Aromat. Plants 2017, 4, 27-34. [CrossRef]

34. Huang, Y.; Zhao, J.; Zhou, L.; Wang, J.; Gong, Y.; Chen, X.; Guo, Z.; Wang, Q.; Jiang, W. Antifungal Activity of the Essential Oil of Illicium verum Fruit and Its Main Component trans-Anethole. Molecules 2010, 15, 7558-7569. [CrossRef] [PubMed]

35. Yuan, C.; Jin, Z.; Xu, X.; Zhuang, H.; Shen, W. Preparation and stability of the inclusion complex of astaxanthin with hydroxypropyl- $\beta$-cyclodextrin. Food Chem. 2008, 109, 264-268. [CrossRef] [PubMed]

36. Hossain, M.A.; Al-Hashmi, R.A.; Weli, A.M.; Al-Riyami, Q.; Al-Sabahib, J.N. Constituents of the essential oil from different brands of Syzigium caryophyllatum L by gas chromatography-mass spectrometry. Asian Pac. J. Trop. Biomed. 2012, 2, S1446-S1449. [CrossRef]

37. Wen, X.; Liu, Z.; Zhu, T. Mass spectrometry and molecular modeling studies on the inclusion complexes between $\alpha, \beta$-cyclodextrins and simvastatin. Chem. Phys. Lett. 2005, 405, 114-117. [CrossRef]

38. Santos, E.H.; Kamimura, J.A.; Hill, L.E.; Gomes, C.L. Characterization of carvacrol beta-cyclodextrin inclusion complexes as delivery systems for antibacterial and antioxidant applications. LWT Food Sci. Technol. 2015, 60, 583-592. [CrossRef]

39. Gong, L.; Li, T.; Chen, F.; Duan, X.; Yuan, Y.; Zhang, D.; Jiang, Y. An inclusion complex of eugenol into $\beta$-cyclodextrin: Preparation, and physicochemical and antifungal characterization. Food Chem. 2016, 196, 324-330. [CrossRef] [PubMed]

Sample Availability: Samples of the compounds are not available from the authors.

(C) 2018 by the authors. Licensee MDPI, Basel, Switzerland. This article is an open access article distributed under the terms and conditions of the Creative Commons Attribution (CC BY) license (http:// creativecommons.org/licenses/by/4.0/). 